\title{
Effects of isoniazid on the proliferation and cytokine production of bladder cancer cells in vitro induced by bacille Calmette-Guérin
}

\author{
R.F.M. BEVERS, E.C. DE BOER, K-H. KURTH and D.H.J. SCHAMHART \\ Department of Urology, University of Amsterdam, The Netherlands
}

Objective To determine the effects of isoniazid (isonicotinic acid hydrazide), used to reduce the serious sideeffects of immunotherapy of superficial bladder cancer with bacille Calmette-Guérin (BCG), on the proliferation and constitutive BCG-induced synthesis of interleukins 6 (IL6) and 8 (IL8) in human bladder cancer cells cultured in vitro.

Materials and methods Three poorly differentiated human cell lines, T24, TCC-SUP and BT-B, were used to study the effect of isoniazid on cell proliferation. Cells were inoculated in tissue culture plates and various concentrations of isoniazid added to the medium. Cell density was then monitored for up to 6 days using a colorimetric assay. To determine the effects of isoniazid on constitutive and BCG-induced cytokine synthesis, cells were cultured in medium containing no additions, BCG, isoniazid or BCG with isoniazid, at various concentrations. Samples of medium were collected regularly for $6 \mathrm{~h}$ and the cytokine content (IL6 and IL8) determined using enzyme-linked immunosorbent assays.
Results Continuous incubation of proliferating T24, TCC-SUP and BT-B cells with isoniazid at concentrations of $0-100 \mu \mathrm{g} / \mathrm{mL}$ did not affect the rate of proliferation. Unlike TCC-SUP and BT-B cells, T24 cells released more IL6 and IL8 during incubation with BCG. At $6 \mathrm{~h}$ after the addition of BCG, the cumulative mean (SD) IL6 and IL8 production of T24 cells was $2.6(0.1)$ and $2.3(0.4) \mathrm{ng}$ per $3 \times 10^{5}$ cells, compared with a constitutive level of $0.1(0.0)$ and $1.3(0.2) \mathrm{ng}$, respectively. There was no significant effect of isoniazid $(1-100 \mu \mathrm{g} / \mathrm{mL})$ on either the constitutive or BCGinduced synthesis of IL6 and IL8 in T24 cells.

Conclusion Assuming an essential role of (tumour) epithelial cells in the local immune response induced by $\mathrm{BCG}$, these in vitro results suggest that the administration of isoniazid does not interfere with this part of the mechanism by which BCG operates.

Keywords Superficial bladder cancer, BCG immunotherapy, isoniazid, cytokines, bladder carcinoma cell lines

\section{Introduction}

Intravesical therapy with BCG against superficial bladder cancer recurrences and carcinoma in situ has been shown to be highly effective in many clinical trials $[1,2]$. Although being an attenuated strain of Mycobacterium bovis without virulence, about $5 \%$ of patients present with moderate to severe local or systemic adverse effects after treatment with BCG, necessitating treatment with the tuberculostatic agent isoniazid [3]. The prophylactic administration of isoniazid, initiated before BCG instillation, has been considered to diminish these side-effects and currently the prophylactic use of isoniazid is being investigated in a clinical trial [4]. However, the prophylactic application of isoniazid assumes that it does not adversely affect the BCG-induced activity against the tumour. Data on potentially interfering effects of isoniazid

Accepted for publication 18 February 1997 on the successive steps involved in the process of BCGinduced antitumour activity are scarce or lacking. Conflicting results about the effect of isoniazid on the BCG-associated immune reaction have been reported; animal studies indicated either an impairment of BCGinduced reactions or absence of an isoniazid-associated effect [5-8]. No impairment by isoniazid of the local immunological stimulation after BCG instillation has been reported in man, suggesting that isoniazid does not affect the antitumour efficacy of BCG [9]. BCG-mediated antitumour activity is probably associated with local immunological phenomena [10], but the detailed mode of action is not clearly understood [11]. When used prophylactically, isoniazid may interfere at all levels within the complex host response to BCG, in addition to its direct antitubercular properties on BCG viability [12]. The present study addresses the direct and indirect effects of isoniazid associated with BCG on urothelial tumour cell lines, modelling the possible interference of isoniazid 
with the initial interaction between BCG and urothelial cells. Presuming that urothelial cells contribute significantly as participants in the locally induced immune response [11,13], the influence of isoniazid on cell proliferation and gene expression was determined in several human bladder tumour cell lines.

\section{Materials and methods}

Three poorly differentiated human cell lines, T24, TCCSUP and BT-B, were used; detailed information (e.g. origin, stage and grade) about the T24 and TCC-SUP cell lines was reported previously [14,15]. The BT-B cell line (kindly provided by Dr A. Böhle, Department of Urology, Medical University Lübeck, Lübeck, Germany) was directly established in vitro from a poorly differentiated (grade 3) surgical specimen (personal communication, Dr A. Böhle and [16]). Stock cultures of the cells were maintained as monolayers in RPMI-1640 medium with $1 \%$ glutamine, supplemented with $10 \%$ fetal calf serum, $100 \mathrm{IU} / \mathrm{mL}$ penicillin and $100 \mu \mathrm{g} / \mathrm{mL}$ streptomycin. Cells were grown at $37^{\circ} \mathrm{C}$ in a humidified $10 \%$ $\mathrm{CO}_{2}$ atmosphere at pH 7.4 until subconfluency. For passage and experiments, cells were trypsinized with $0.05 \%$ trypsin and $0.02 \%$ EDTA in PBS $(8 \mathrm{~g}$ of $\mathrm{NaCl}$, $0.2 \mathrm{~g}$ of $\mathrm{KCl}, 1.16 \mathrm{~g}$ of $\mathrm{Na}_{2} \mathrm{HPO}_{4} .2 \mathrm{H}_{2} \mathrm{O}$ and $0.2 \mathrm{~g}$ of $\mathrm{KH}_{2} \mathrm{PO}_{4}$ per litre at $\mathrm{pH} 7.4$ ). Cultures were screened routinely for mycoplasma. All tissue culture chemicals were obtained from Flow Laboratories (Irvine, Scotland). Tissue culture plastics were from Costar (Cambridge, MA, USA). A vial-lyophilized BCG, strain Connaught (Connaught Laboratories, North York, Canada) containing $1.9 \times 10^{8}$ c.f.u. of BCG per vial was reconstituted in prewarmed culture medium to the appropriate concentration for experiments.

To determine the effect of isoniazid on bladder tumour cell proliferation, $2.5 \times 10^{3}$ cells were inoculated in 96-well flat-bottom tissue culture plates containing $100 \mu \mathrm{L}$ medium. After $24 \mathrm{~h}$ the cells were refreshed with RPMI-1640 $(100 \mu \mathrm{L})$ without or with various concentrations $(1-100 \mu \mathrm{g} / \mathrm{mL})$ of isoniazid (Sigma, St Louis, MI, USA). Cell density was monitored for up to 6 days using a colorimetric assay measuring the formation of a formazan dye, soluble in aqueous solutions, from XTT (sodium 3'-[1-(phenylaminocarbonyl)-3,4-tetrazolium]bis (4-methoxy-6-nitro) benzene sulphonic acid hydrate) [17]. Briefly, $50 \mu \mathrm{L}$ XTT solution, containing $1 \mathrm{mg} \mathrm{XTT}$ per $1 \mathrm{~mL}$ RPMI-1640 and $0.383 \mathrm{mg} \mathrm{N}$-methyl dibenzopyrazine methyl sulphate (Sigma) per $1 \mathrm{~mL}$ PBS, was added to the cultures. After incubation for $3 \mathrm{~h}$ at $37^{\circ} \mathrm{C}$, the optical density was read at $490 \mathrm{~nm}$ and $650 \mathrm{~nm}$ as a reference wavelength using a microplate reader (Thermomax, Molecular Devices, Sopachem, Lunteren, The Netherlands). The spectrophotometer was blanked on the first column of control wells containing medium (without cells) and XTT solution; isoniazid did not interfere with the assay. In some experiments, data obtained with the XTT assay were verified by cell counting with a Coulter counter and/or a haemocytometer.

To determine the effects of isoniazid on constitutive and BCG-induced cytokine synthesis, cells $\left(3 \times 10^{5}\right)$ were cultured for $24 \mathrm{~h}$ in 24-well plates containing $1 \mathrm{~mL}$ medium/well. Subsequently, the medium was replaced with medium containing (i) no additions, (ii) BCG (1 or $5 \times 10^{6}$ c.f.u.), (iii) isoniazid $(100 \mu \mathrm{g} / \mathrm{mL}$ ) or (iv) BCG and isoniazid at these concentrations. Medium was collected at regular intervals for $6 \mathrm{~h}$, centrifuged and stored at $-20^{\circ} \mathrm{C}$ before cytokine content was determined. IL6 was quantified as described previously, using a humanspecific, oligoclonal ELISA (Medgenix, Fleurus, Belgium) [13]. IL8 was determined with an ELISA developed by CLB (Amsterdam, The Netherlands) [18]; the detection limits of the two assays were $3 \mathrm{pg} / \mathrm{mL}$ IL6 and $5 \mathrm{pg} / \mathrm{mL}$ IL8.

To test for differences between groups, a series of oneway ANOVAs with equal or unequal size was used. When significant differences $(P<0.05)$ were found by analysis of variance, Duncan's multiple-range test [19], or for unequal numbers of replications Duncan's multiple-range test adjusted by Kramer, was applied $(P=$ 0.05) [20]. For differences between groups, paired comparisons were assessed using Student's $t$-test.

\section{Results}

Addition of isoniazid at concentrations of $1-100 \mu \mathrm{g} / \mathrm{mL}$ at $24 \mathrm{~h}$ after inoculation appeared to have no effect on the proliferation of T24, TCC-SUP and BT-A cells (Fig. 1). Initially, the constitutive and BCG-induced upregulation of IL6 and IL8 of the three bladder cancer cell lines was determined. BCG was applied as an inducer, as a BCGassociated upregulation of the synthesis of various cytokines has been reported in the T24 bladder cancer cell line in vitro [13]. The present results indicated that BCG upregulated the synthesis of both IL6 and IL8 in T24 cells, but not in TCC-SUP and BT-A cells (Table 1). Moreover, T24 cells showed a profound constitutive synthesis of IL8 compared with BT-B and TCC-SUP cells.

Because both IL6 and IL8 synthesis were upregulated by BCG in T24 cells, the effect of $1-100 \mu \mathrm{g} / \mathrm{mL}$ isoniazid on the constitutive and BCG-induced synthesis of IL6 and IL8 was determined in this cell line. However, a control experiment was performed to determine whether the penicillin and streptomycin in the culture medium interfered with the capacity of BCG to induce cytokine synthesis in T24 cells. The BCG-associated upregulation of IL6 and IL8 in the presence and absence of penicillin and streptomycin was similar, suggesting that there was 

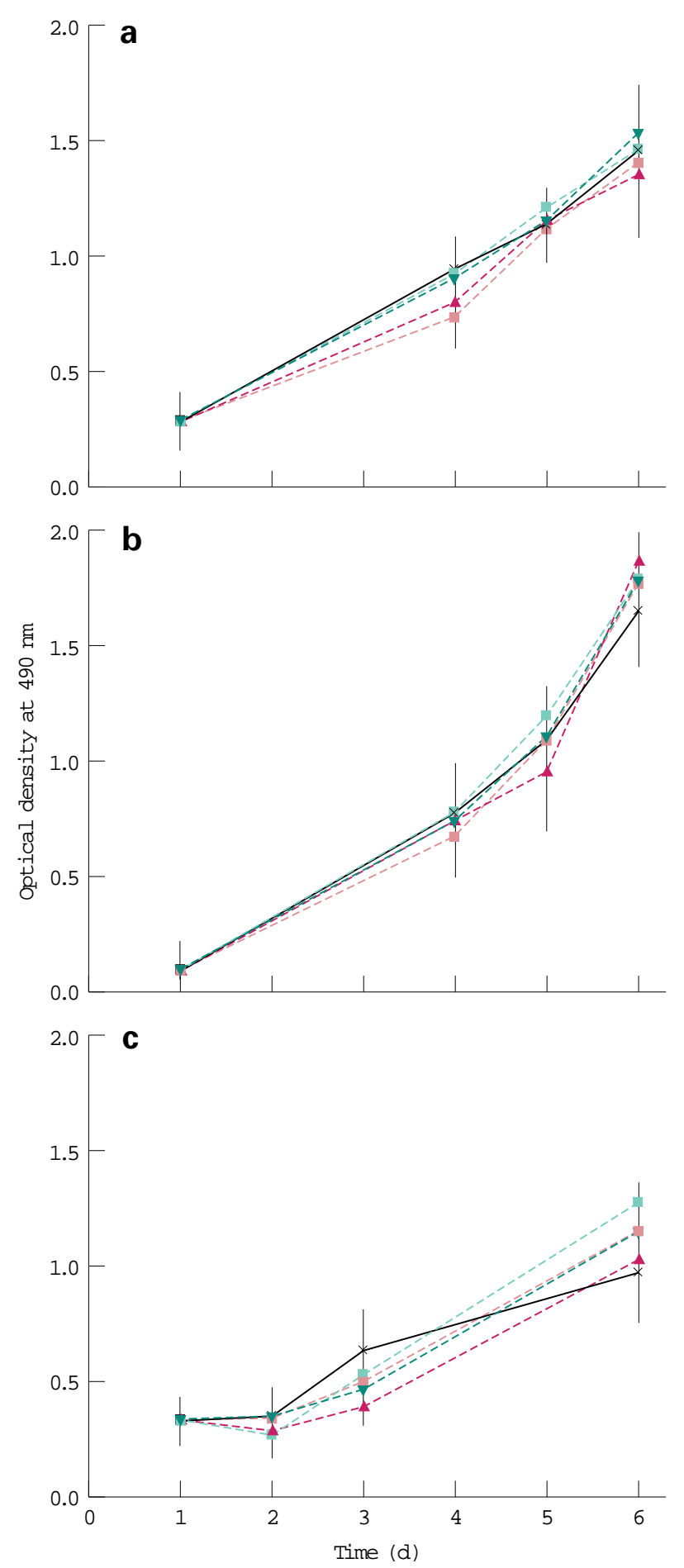

Fig. 1. Proliferation of the bladder carcinoma cell lines, a, BT-B, b, TCC-SUP and c, T24, in the presence of various concentrations of isoniazid. At $24 \mathrm{~h}$ after inoculation, the cell cultures were refreshed with medium containing 0 (crosses), 1 (closed squares), 10 (down triangles), 50 (up triangles) or 100 (open squares) $\mu \mathrm{g} / \mathrm{mL}$ isoniazid. The number of cells was determined using the XTT assay and expressed as the optical density at $490 \mathrm{~nm}$.
Table 1 Cumulative production of IL6 and IL8 in the medium of BT-B, TCC-SUP and T24 cells during $6 \mathrm{~h}$ incubation in the absence and presence of $\mathrm{BCG}$

\begin{tabular}{cll}
\hline & \multicolumn{2}{l}{ Mean (sD) concentration $\left(\mathrm{ng} / 3 \times 10^{5}\right.$ cells $)$} \\
\cline { 2 - 3 } & IL6 & IL8 \\
\hline BT-B & & \\
- BCG & $0.3(0.0)$ & $<<^{*}$ \\
+ BCG & $0.4(0.1)$ & $<<$ \\
TCC-SUP & & $<<$ \\
- BCG & $1.1(0.1)$ & $<<$ \\
+ BCG & $1.0(0.1)$ & $1.3(0.2)$ \\
T24 & & $2.3(0.4) \dagger$ \\
- BCG & $0.1(0.0)$ & \\
+ BCG & $2.6(0.1) \dagger$ & \\
\hline
\end{tabular}

${ }^{*}<<$ indicates an IL8 concentration of $<10 \mathrm{pg} / \mathrm{mL} . \dagger P<0.01$ compared to cytokine accumulation in the absence of $\mathrm{BCG}$.

no interference with the BCG-induced upregulation of the cytokines within the duration of the experiments. The presence of isoniazid did not interfere with the observed continuous, linear increase of either constitutive or BCG-induced production of IL6 and IL8 (Table 2). In addition, there was no effect of isoniazid on the relatively high constitutive synthesis of IL6 in TCC-SUP cells (results not shown).

\section{Discussion}

Several lines of evidence indicate that (specialized) epithelial cells, such as mature pulmonary epithelial cells, may contribute to the host defence system through interactions with inflammatory cells [21]. It has been suggested that uroepithelial cells are part of a mucosal cytokine network, depending on microbial stimulation

Table 2 Cumulative production of constitutive and BCG-induced IL6 and IL8 in the medium of T24 cells during $6 \mathrm{~h}$ in the absence and presence of isoniazid

\begin{tabular}{rll}
\hline & \multicolumn{2}{l}{ Mean $(\mathrm{sD})$ concentration $(\mathrm{ng} / \mathrm{mL})$} \\
\cline { 2 - 3 } Isoniazid $(\mu \mathrm{g} / \mathrm{mL})$ & $\mathrm{IL6}$ & $\mathrm{IL} 8$ \\
\hline$-\mathrm{BCG}$ & & \\
0 & $0.3(0.0)$ & $1.1(0.0)$ \\
1 & $0.3(0.1)$ & $1.3(0.3)$ \\
10 & $0.3(0.2)$ & $0.9(0.2)$ \\
100 & $0.3(0.1)$ & $0.9(0.0)$ \\
$+\mathrm{BCG}$ & & \\
0 & $2.3(0.4)$ & $2.2(0.9)$ \\
1 & $2.1(0.2)$ & $2.0(0.4)$ \\
10 & $2.2(0.0)$ & $1.7(0.0)$ \\
100 & $2.3(0.2)$ & $1.7(0.2)$ \\
\end{tabular}


of epithelial cells, as is the case in urinary tract infections [22]. During intravesical therapy of superficial bladder cancer with BCG, urothelial (tumour) cells are exposed to BCG mycobacteria. In vitro, this situation has been shown to upregulate cytokine synthesis by human bladder tumour cells $[13,18]$; some of these in vitro observations seem to be analogous to observations in vivo $[11,18,23]$ supporting the notion that urothelial cells may contribute to the modulation of the BCG-induced immune reaction that is probably important for antitumour activity.

Isoniazid is one of the most widely used antituberculosis drugs, although its precise target of action on mycobacteria is unknown [24,25]. In addition, adverse effects on eukaryotic cells, such as chromosomal aberrations, have been noted by some but not by others $[24,26]$. The latter report suggests a possible direct effect of isoniazid on urothelial cells during BCG therapy of superficial bladder cancer. The present results indicate no effect, stimulatory or inhibitory, of isoniazid on cell proliferation and cytokine (IL6 and IL8) synthesis, either constitutive or BCG-induced, of bladder cancer cell lines in vitro. These results were obtained at isoniazid concentrations comparable to those found in the urine (38.0, SD $60.9, \mathrm{mg} / \mathrm{mL}$ urine) of patients treated with isoniazid (300 mg) orally the day before, $2 \mathrm{~h}$ before and the day after BCG instillation [9]. This protocol of isoniazid administration is currently under investigation in man (EORTC protocol 30911) [4].

In conclusion, the present results suggest that the administration of isoniazid does not interfere with the postulated, modulating role of cytokine-producing urothelial cells after intravesical BCG instillations. However, these results do not exclude possible interference of isoniazid with additional steps of the BCG-induced cascade.

\section{Acknowledgements}

This study was supported in part by a grant of Connaught Laboratories Limited, North York, Ontario, Canada and the BUWO foundation, Amsterdam, The Netherlands.

\section{References}

1 Herr HW, Pinsky CM, Whitmore WF Jr et al. Experience with intravesical bacillus Calmette-Guérin therapy of superficial bladder tumors. Urology 1985; 25: 119-23

2 Lamm DL, Blumenstein BA, Crawford ED et al. A randomized trial of intravesical doxorubicin and immunotherapy with bacille Calmette-Guérin for transitional cell carcinoma of the bladder. New Engl J Med 1991; 325: 1205-9

3 Lamm DL, Van der Meijden APM, Morales A et al. Incidence and treatment of complications of bacillus Calmette Guérin intravesical therapy in superficial bladder cancer. $J$ Urol 1992; 147: 596-600

4 Van der Meijden APM. Practical approaches to the prevention and treatment of adverse reactions to BCG. Eur Urol 1995; 27 (suppl 1): 23-8

5 Blanden RV, Lefford MJ, Mackaness GB. The host response to Calmette-Guérin bacillus infection in mice. J Exp Med 1969; 129: 1079-107

6 Chung EB, Zbar B, Rapp HJ. Tumor regression mediated by Mycobacterium bovis (strain BCG). Effects of isonicotinic azid hydrazide, cortisone acetate, and antithymocyte serum. J Natl Cancer Inst 1973; 51: 241-50

7 Albert NE, Sparks FC, Lytton B. The effect of intramural injection of immunotherapeutic agents on bladder histology and systemic humoral response. Invest Urol 1978; 16: 134-9

8 De Boer LC, Steerenberg PA, Van der Meijden APM et al. Impaired immune response by isoniazid treatment during intravesical BCG administration in the guinea pig. $J$ Urol 1992; 148: 1577-82

9 Stassar MJJG, Vegt PDJ, Steerenberg PA et al. Effects of isoniazid (INH) on the BCG-induced local immune response after intravesical BCG therapy for superficial bladder cancer. Urol Res 1994; 22: 177-84

10 De Reijke ThM, De Boer EC, Kurth KH, Schamhart DHJ. Urinary cytokines during intravesical Bacillus Calmette-Guerin therapy for superficial bladder cancer: processing, stability and prognostic value. J Urol 1996; 155: $477-82$

11 Jackson AM, James, K. Understanding the most successful immunotherapy for cancer. The Immunologist 1994; 2: 208-15

12 Seth V. Isoniazid - the pivot of chemotherapy in tuberculosis. Indian Pediatrics 1990; 27: 119-23

13 De Reijke ThM, Vos PCN, De Boer EC et al. Cytokine production by the human bladder carcinoma cell line T24 in the presence of bacillus Calmette-Guerin (BCG). Urol Res 1993; 21: 349-52

14 Johansson SL, Unsgaard B, O'Toole. Cell lines from urinary bladder tumors. In Hay RJ ed., Atlas of Human Tumor Cell Lines Academic Press, 1994: 341-57

15 Masters JRW, Hepburn PJ, Walker L et al. Tissue culture model of transitional cell carcinoma: characterization of twenty-two human urothelial cell lines. Cancer Res 1986; 46: 3630-6

16 Van der Bosch J, Rüller S, Horn D et al. Density dependent tumor cell death and reversible cell cycle arrest: mutually exclusive modes of monocyte mediated growth control. Exp Cell Res 1990; 187: 185-92

17 Roehm NW, Rodgers GH, Hatfield SM et al. An improved colorimetric assay for cell proliferation and viability utilizing the tetrazolium salt XTT. J Immunol Methods 1991; 142: 257-65

18 De Boer EC, Schamhart DHJ, Somogyi L, Kurth KH. IL8 and onset of BCG-induced immune response. Urol Res 1995; 23: 250 (P22)

19 Duncan DB. Multiple range and multiple $F$ tests. Biometrics 1955; 11: 1-10

20 Kramer CY. Extension of multiple range tests to groups 
means with unequal numbers of replications. Biometrics 1956; 12: 307-12

21 Thompson AB, Robbins RA, Romberger DJ et al. Immunological functions of the pulmonary epithelium. Eur Respir J 1995; 8: 127-49

22 Hedges S, Agaca W, Svensson M, Sjögren A et al. Uroepithelial cells are part of a mucosal cytokine network. Infect Immun 1994; 62: 2315-21

23 Esuvaranathan $\mathrm{K}$, Alexandroff $\mathrm{AB}$, McIntyre $\mathrm{M}$ et al. Interleukin- 6 production by bladder tumors is upregulated by BCG immunotherapy. J Urol 1995; 154: 572-5

24 Takayama K, Wang L, David HL. Effect of isoniazid on the in vivo mycolic acid synthesis, cell growth, and viability of Mycobacterium tuberculosis. Antimicrobial Agents Chemother 1972; 2: 29-35

25 Hillar A, Loewen PC. Comparison of isoniazid oxidation catalyzed by bacterial catalase-peroxidase and horseradish peroxidase. Arch Biochem Biophys 1995 323: 438-46

26 Rohrborn G, Miltenburger HG, Radenbach KL. A correlated study of the cytogenetic effect of Isoniazid (INH) on cell systems of mammals and man conducted by thirtheen laboratories. Introductory remarks. Human Gen 1978; 42: $3-7$

27 Jaju M, Jaju M, Ahuja YR. Combined and individual effects of isoniazid and thiacetazone on human lymphocyte chromosomes in vitro and in vivo. Human Toxicol 1984; 3: $373-82$

\section{Authors}

R.F.M. Bevers, MD, Urologist. Present address, Central Military Hospital, PB 9000, Utrecht, The Netherlands.

E.C. de Boer, PhD, Biologist.

K-H.Kurth, MD, PhD, Professor and Head of Department of Urology, D.H.J. Schamhart, PhD, Biologist.

Correspondence: Dr D.H.J. Schamhart, Department of Urology, University of Amsterdam, Meibergdreef 9, 1105 AZ Amsterdam, The Netherlands. 